\title{
Inclusion of Kl67 significantly improves performance of the PREDICT prognostication and prediction model for early breast cancer
}

Gordon C Wishart', Emad Rakha², Andrew Green², lan Ellis², Hamid Raza Ali ${ }^{3}$, Elena Provenzano ${ }^{3}$, Fiona M Blows ${ }^{3}$, Carlos Caldas ${ }^{3}$ and Paul DP Pharoah ${ }^{3^{*}}$

\begin{abstract}
Background: PREDICT (www.predict.nhs.uk) is a prognostication and treatment benefit tool for early breast cancer (EBC). The aim of this study was to incorporate the prognostic effect of Kl67 status in a new version (v3), and compare performance with the Predict model that includes HER2 status (v2).

Methods: The validation study was based on 1,726 patients with EBC treated in Nottingham between 1989 and 1998. KI67 positivity for PREDICT is defined as $>10 \%$ of tumour cells staining positive. ROC curves were constructed for Predict models with (v3) and without (v2) KI67 input. Comparison was made using the method of DeLong.

Results: In $1274 \mathrm{ER}+$ patients the predicted number of events at 10 years increased from 196 for $\mathrm{V} 2$ to 204 for $\mathrm{V} 3$ compared to 221 observed. The area under the ROC curve (AUC) improved from 0.7611 to $0.7676(p=0.005)$ in ER+ patients and from 0.7546 to 0.7595 ( $p=0.0008$ ) in all 1726 patients (ER+ and ER-).

Conclusion: Addition of KI67 to PREDICT has led to a statistically significant improvement in the model performance for ER+ patients and will aid clinical decision making in these patients. Further studies should determine whether other markers including gene expression profiling provide additional prognostic information to that provided by PREDICT.
\end{abstract}

Keywords: Breast cancer, KI67, Prognostic model

\section{Background}

Selection of appropriate patients for adjuvant chemotherapy following surgery for early breast cancer remains one of the greatest challenges for clinicians involved in the management of patients with early breast cancer. Recent debate has focused on patients with oestrogen receptor (ER) + tumours, following identification that ER+ tumours can be split into at least two specific molecular subtypes, Luminal A and Luminal B, with a marked difference in tumour characteristics and prognosis [1,2]. Luminal A tumours in general have an excellent prognosis, and are unlikely to benefit from chemotherapy. Luminal B tumours have a worse prognosis than Luminal A tumours and can be identified by the high expression of specific proliferation-related genes such as KI67 or

\footnotetext{
* Correspondence: pp10001@medschl.cam.ac.uk

${ }^{3}$ Department of Oncology, University of Cambridge, Strangeways Research Laboratory, Worts Causeway, Cambridge CB1 8RN, UK

Full list of author information is available at the end of the article
}

Aurora A kinase (AURKA). More recently additional subtypes of ER+ tumours have been identified [3]. The classifications based on gene expression can be recapitulated using immunohistochemistry (IHC) $[4,5]$. While AURKA expression has been shown to be a more powerful prognosticator than KI67 [6], KI67 has been advocated as the marker of choice for measuring and monitoring tumour proliferation [7]. Furthermore, KI67 expression has been used with other IHC markers to identify the proliferative subgroup of HER2- \& ER+ cases with a poor outcome [8], who may benefit from adjuvant chemotherapy.

PREDICT is an online prognostication and treatment benefit tool (www.predict.nhs.uk) that is based on clinicopathological factors including tumour size, tumour grade, lymph node status, ER status, HER2 status and mode of detection. PREDICT was developed using cancer registry data on 5,694 women treated in East Anglia from 1999-2003. Breast cancer mortality models for ER positive and ER negative tumours were constructed using Cox proportional 
hazards, adjusted for known prognostic factors and mode of detection (symptomatic versus screen-detected) [9]. The Cox models were used to derive the baseline survivor function and the hazard ratio associated with each prognostic factor. PREDICT uses the baseline survivor function and the hazard ratio estimates (Table 1) to predict survival for a patient with a specific set of prognostic factors without adjuvant therapy and with adjuvant hormone therapy or chemotherapy assuming the relative risk reductions reported by the Early Breast Cancer Trialists Collaborative Group overview [10]. The survival estimates for an individual patient are based on the average co morbidity for women with breast cancer of a similar age. The original model (v1), which provides estimates of 5-and 10-year survival as well as absolute treatment benefits, has been validated in independent case-cohorts from the UK [9] and Canada [11]. HER2 status was subsequently added to PREDICT by incorporating an external estimate of the hazard ratio associated with HER2 positivity - i.e. an estimate from a different data set than that used to derive PREDICT v1. Following inclusion of HER2 status as an input variable, the updated Predict model (v2) provided better breast cancer specific survival estimates than Adjuvant, especially in the subset of patients with HER2 positive tumours [12].

There appears little doubt that KI67 has great potential as a prognostic and predictive factor in early breast cancer [13], but integration into routine clinical management has to date been hampered by a failure to identify the optimal approach for its incorporation into prognostic tools [14-16]. This study was not intended to inform the current debate on finding the optimal threshold for KI67 positivity or to promote the value of KI67 as a prognostic marker. The aim of this study was to incorporate the prognostic effect of KI67 status in a new version of Predict (v3), and compare performance with the current Predict model that includes HER2 status (v2) in an independent patient cohort.

\section{Methods}

Prognostic effect of tumour KI67 status

An estimate for the prognostic effect of KI67 status was based on an analysis of data from the SEARCH (studies of epidemiology and risk factors in cancer heredity) study [6]. SEARCH is a large prospective population-based study of women diagnosed with breast cancer, including prevalent cases diagnosed before the age of 55 years during 1991-1996 and still alive in 1996, and incident cases consisting of women under the age of 70 years diagnosed after 1996. From the SEARCH study, KI67 was available for a total of 2,436 patients (1,835 ER positive, 601 ER negative) and immunohistochemical (IHC) expression was categorised into one of five groups $(0 \%, 1-10 \% .11-33 \%, 34-$ $66 \%,>66 \%$ ) according to an Allred proportion score. KI67 positivity, defined as $>10 \%$ of tumour cells staining positive, was associated with a multi-variable adjusted hazard ratio (HR) for breast cancer specific mortality of 1.3 in patients with ER-positive tumours. KI67 was dichotomised because there was little evidence for any trend in the HR associated with increasing KI67 score. PREDICT v3 was generated by applying the HR associated with KI67 to the baseline hazards used in PREDICT v2 such that KI67negative ER-positive tumours have a relative hazard of 0.89 and the KI67-positive ER-positive tumours have a relative hazard of 1.16. The relative hazard between KI67positive and KI67-negative is then 1.3 with an average relative hazard of one. PREDICT v2 and PREDICT v3 are the same for ER-negative tumours as KI67 is not associated with prognosis in this sub-group.

\section{Validation study population}

Data were available for 2,232 cases of invasive breast cancer treated in Nottingham from 1989-1998. Of these, 506 node-negative cases were excluded due to inadequate axillary node staging $(<4$ nodes sampled), leaving 1,726 patients (ER-, $\mathrm{n}=452$; $\mathrm{ER}+, \mathrm{n}=1,274$ ) for the validation study. Data are presented in detail for the 1,274 ER positive patients.

Information obtained from the Nottingham dataset included age at diagnosis, histological grade, tumour size, number of positive lymph nodes, ER status, HER2 status, KI67 and type of adjuvant systemic therapy (none, chemotherapy, endocrine therapy, both). Mean imputation, with the missing value replaced by the mean for that variable, was used to account for missing data for tumour size, tumour grade, HER2 status and KI67 status. The number of cases with missing data for each variable is shown in Table 2. Chemotherapy regimens were considered to be

Table 1 Hazard ratio estimates for prognostic variables used by PREDICT ${ }^{1}$

\begin{tabular}{ll}
\hline $\begin{array}{l}\text { Prognostic variable } \\
\text { (Categories) }\end{array}$ & Hazard ratio per unit increase in variable category \\
\cline { 2 - 2 } Node status $(0,1,2$ to 4,5 to $9,10+)$ & ER+ \\
Tumour size in mm <10, 10 to 19,20 to 29,30 to $49,50+)$ & 1.75 \\
Grade (Low, intermediate, high) & 1.43 \\
Screen detected & 2.33 \\
\hline
\end{tabular}

1 Published in Wishart et al. [9]. 
Table 2 Observed and predicted breast cancer deaths at ten years by clinical characteristics in ER positive cases

\begin{tabular}{|c|c|c|c|c|}
\hline & \multirow{2}{*}{$\begin{array}{l}\text { Number } \\
\text { of cases }\end{array}$} & \multicolumn{3}{|c|}{ Breast cancer deaths (number) } \\
\hline & & Observed & PREDICT v2 & PREDICT V3 \\
\hline$\overline{\text { Total }}$ & & 221 & 196 & 204 \\
\hline \multicolumn{5}{|c|}{ Age group } \\
\hline$<40$ & 67 & 15 & 13 & 14 \\
\hline $40-49$ & 274 & 52 & 44 & 46 \\
\hline $50-49$ & 436 & 70 & 59 & 61 \\
\hline $60+$ & 497 & 84 & 79 & 83 \\
\hline \multicolumn{5}{|l|}{ Size } \\
\hline$<10$ & 144 & 7 & 9 & 9 \\
\hline $10-19$ & 574 & 63 & 58 & 60 \\
\hline $20-29$ & 404 & 110 & 83 & 87 \\
\hline $30-49$ & 140 & 39 & 41 & 43 \\
\hline $50+$ & 11 & 2 & 4 & 4 \\
\hline Missing & 1 & 0 & 0 & 0 \\
\hline \multicolumn{5}{|c|}{ Node status } \\
\hline Negative & 709 & 75 & 63 & 65 \\
\hline $1+$ & 241 & 48 & 39 & 41 \\
\hline $2-4+$ & 184 & 58 & 55 & 58 \\
\hline $5-9+$ & 37 & 21 & 19 & 20 \\
\hline $10+$ & 6 & 4 & 5 & 5 \\
\hline Missing & 97 & 15 & 14 & 14 \\
\hline \multicolumn{5}{|l|}{ Grade } \\
\hline 1 & 235 & 18 & 10 & 10 \\
\hline 2 & 528 & 72 & 62 & 63 \\
\hline 3 & 395 & 127 & 111 & 119 \\
\hline Missing & 116 & 4 & 13 & 13 \\
\hline \multicolumn{5}{|c|}{ HER2 status } \\
\hline Negative & 792 & 169 & 125 & 131 \\
\hline Positive & 77 & 31 & 23 & 25 \\
\hline Missing & 405 & 21 & 48 & 48 \\
\hline
\end{tabular}

first generation, as the patients were treated between 1989 and 1998.

This research was carried out in compliance with the Helsinki Declaration. SEARCH is approved by the East of England - Cambridge Research Ethics Committee (02/ 5/42) and the Nottingham Breast Cancer study is approved by the Nottingham Research Ethics Committee 2 (REC number C2020313).

The primary endpoint was 10-year breast cancer specific survival (BCSS). Predicted survival was calculated for each patient using v2 and v3 of PREDICT. Model calibration was analysed as a comparison of the predicted mortality estimates from each model with the observed mortality. In addition to comparing calibration in the complete data set, we evaluated calibration within strata of other prognostic variables. We also evaluated calibration within quintile of predicted mortality. A goodness-of-fit test was carried out by using a $\chi^{2}$-test based on the observed and predicted number of events within each quintile ( 5 d.f.). Model discrimination was evaluated by calculating the area under the receiver-operator-characteristic curve (AUC) calculated for 10-year mortality. This is a measure of how well each version of the model identifies those patients with worse survival. The AUC is the probability that the predicted mortality from a randomly selected patient who died will be higher than the predicted mortality from a randomly selected survivor. Comparison between v2 and v3 was made using the method of DeLong [16].

\section{Results}

\section{Calibration}

In the 1,274 patients with ER-positive tumours, there were 221 breast cancer deaths after ten years of follow-up. The calibration of PREDICT v2 and PREDICTv3 was good with PREDICT v3 slightly out performing v2. V2 of PREDICT estimated 196 deaths compared to 204 deaths estimated by v3. The observed and predicted numbers of deaths by clinical characteristics are shown in Table 2 . PREDICT performed well in all sub groups, with v3 performing better than v2 in all but the cases with large tumours $(>30 \mathrm{~mm})$ or cases with ten or more positive nodes. Calibration of PREDICT v3 across quintiles of predicted risk was good (Figure 1, goodness-of-fit $\mathrm{P}=.065$ ). The number of deaths in the 453 ER-negative cases predicted by PREDICT v2/v3 was the same as the number observed $(\mathrm{n}=142)$.

\section{Discrimination}

The discrimination of both versions of PREDICT was also good and again was slightly better in v3 than in v2. Discrimination, as estimated from the AUC significantly improved from 0.7611 for v2 to 0.7676 for v3 ( $\mathrm{p}=$ 0.005). The receiver operating characteristics curves are shown in Figure 2. When all 1,726 patients (ER+ and ER-) were analysed, the addition of KI67 to PREDICT significantly improved the AUC from 0.7546 to 0.7595 $(\mathrm{p}=0.0008)$.

\section{Discussion and conclusions}

Addition of KI67 to the Predict model has significantly improved both calibration and discrimination of PREDICT and this version (v3) of the model is now freely available online at www.predict.nhs.uk. It is anticipated that this improvement in model performance will contribute to more accurate predictions of the chemotherapy benefit for individual patients. Both versions of PREDICT, with (v3) and without KI67 (v2), underestimated the number of breast cancer deaths by $8 \%$ and $11 \%$ respectively in this case cohort. This may be partly explained by the fact 


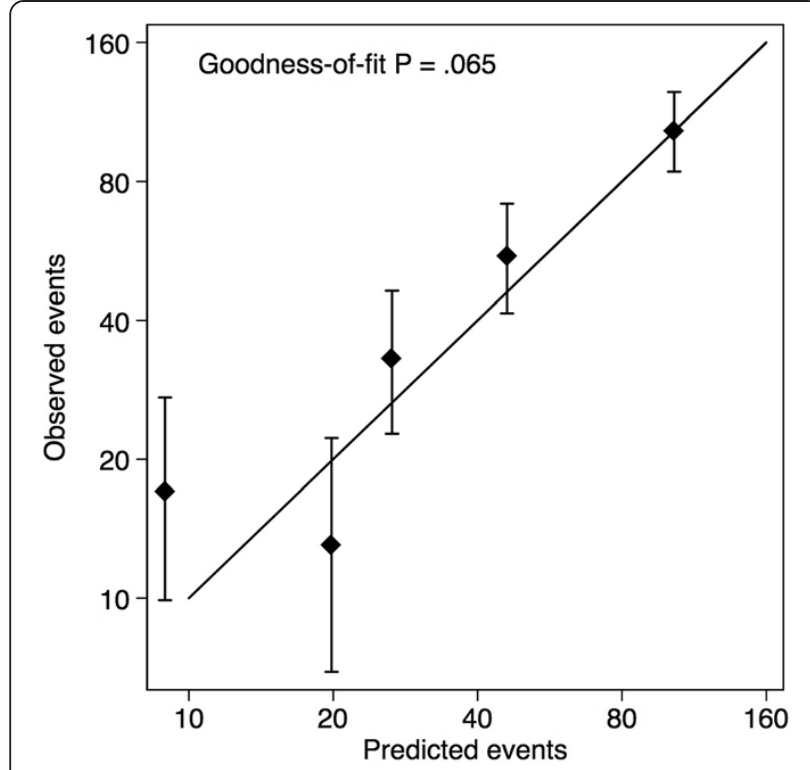

Figure 1 Calibration plots of observed outcomes with $95 \%$ confidence intervals against predicted outcomes by quartiles of the predicted value.

that the Nottingham dataset is an older cohort of patients diagnosed from 1989 to 1998, whereas PREDICT is based on women diagnosed in East Anglia, UK from 1999 to 2003.

Several multi-gene expression assays are now available for use in breast cancer management. They are based on

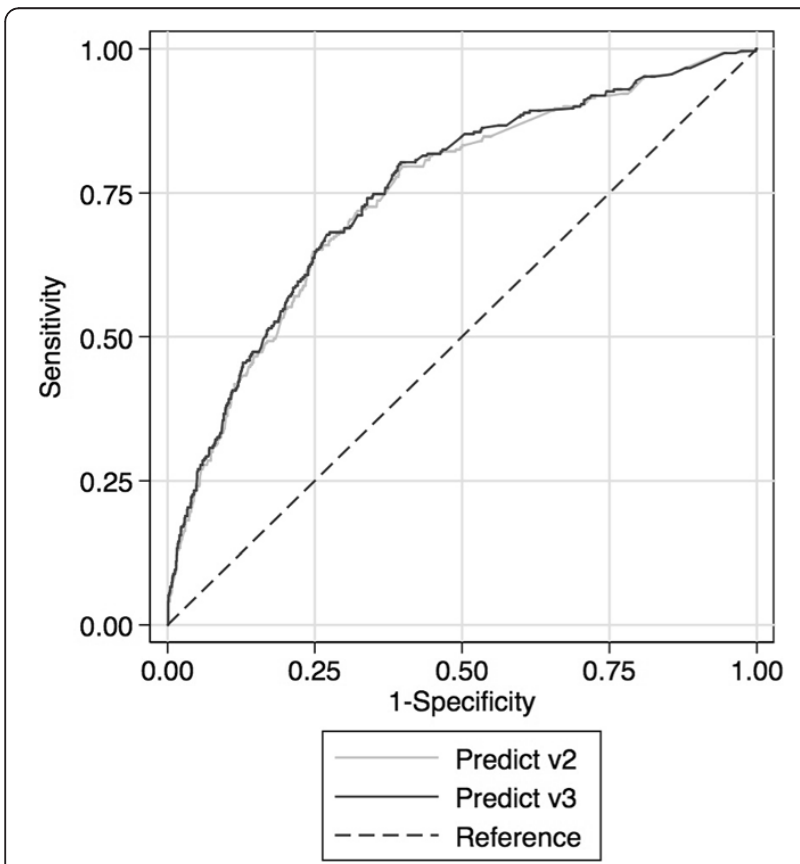

Figure 2 Receiver operator characteristic curves for breast cancer specific mortality in 1,274 cases with ER positive disease based on PREDICT v2 and PREDICT v3.
mRNA expression in up to 70 cell cycle and proliferation genes [17-19]. The Genomic Health recurrence score (Oncotype $\mathrm{Dx}^{\oplus} \mathrm{RS}$ ) is a prognosticator (breast cancer recurrence) based on a 21 gene expression profile. Oncotype $\mathrm{Dx}^{\circledast}$ has recently been recommended by NICE (DG10) for use in women with oestrogen receptor positive, lymph node negative and HER2 negative early breast cancer to guide chemotherapy decisions if the person is assessed as being at intermediate risk using routine parameters, and where the information on the biological features of the cancer provided by Oncotype $\mathrm{DX}^{\circledast}$ is likely to help in predicting the course of the disease. While the analytic validity of the gene expression component of the Oncotype $\mathrm{DX}^{\curvearrowleft} \mathrm{RS}$ is well established, the clinical validity - i.e the calibration and discrimination of the recurrence predictions of the Oncotype DX ${ }^{\oplus S}$ - has not been published. Furthermore, the incremental improvement in discrimination for the Oncotype $\mathrm{DX}^{\ominus} \mathrm{RS}$ recurrence predictions over the established prognostic factors included in PREDICT is not known. A recent study has reported that the Oncotype $\mathrm{DX}^{\odot} \mathrm{RS}$ is an independent prognostic factor in ER-negative, HER2-negative tumours but the improvement in discrimination from the RS compared to clinical variables was less than the improvement obtained from the improvement obtained by IHC4, an immunohistochemistry test that includes KI67 [20]. Another recent study explored the addition of the 70-gene signature (MammaPrint $^{\mathrm{TM}}$ ) to Predict (v2) in 427 patients with early stage breast cancer and found no significant improvement in 5- or 10-year survival predictions [21].

There has been considerable debate about the utility of KI67 IHC in routine clinical practice, partly because the analytic validity of KI67 measurement by IHC is suboptimal and the optimal threshold for identifying KI67 positive tumours is not known. However, while such considerations are germane to the incorporation on KI67 IHC into a multi-variable risk prediction model, issues around analytic validity are not of primary importance in this study. The KI67 parameter included in the PREDICT model was derived from data from one study - SEARCH. The validation of the PREDICT risk prediction model utilized data from a completely independent case-cohort for which KI67 had been measured in a completely different laboratory. It is thus likely that the standardization of KI67 was sub-optimal. The calibration and discrimination of PREDICT improved despite this limitation. This emphasizes the point that even a marker measured sub-optimally can have clinical validity when that marker is used in the context of risk prediction.

Inclusion of HER2 and KI67 in PREDICT has significantly improved the performance to estimate breast cancer specific mortality. It is likely that the estimated absolute 10-year benefits of adjuvant chemotherapy will be similarly improved. The authors recognise that there 
may be a better way to dichotomise KI67 positivity, but the $10 \%$ cut-off has been shown previously to be optimal [22], and the use of this simple cut off in our study demonstrated the validity of KI67 as a prognostic marker with improved performance of the PREDICT model. This model, based on traditional clinico-pathological factors as well as IHC detection of 3 IHC markers (ER, HER2 \& KI67), now provides an ideal platform to test the incremental improvement with the addition of any new prognostic marker or gene expression profile. Inclusion of progesterone receptor (PR) is the only widely used IHC marker not currently included in the PREDICT model and future studies will explore inclusion of PR. The version of PREDICT that includes KI67 is quick to use, free and available for decision making at the clinician desk-top. Oncotype Dx is now widely used in the USA, but the cost has prevented worldwide adoption for risk assessment in patients with early-stage ER-positive breast cancer. We believe that further research should address whether gene-expression profiles such as Oncotype Dx actually provide any incremental benefit in risk prediction to that currently provided by the most recent version of PREDICT.

Addition of KI67 to PREDICT has led to a statistically significant improvement in the model performance for ER+ patients and will aid clinical decision making in these patients. Further studies should determine whether other markers including gene expression profiling provide additional prognostic information to that provided by PREDICT.

\section{Competing interests}

The authors declared that they have no competing interests.

\section{Authors' contributions}

GCW designed the study and drafted the manuscript. ER generated and scored the Nottingham tissue micro-array data, AG generated and managed the Nottingham tissue micro-array data, IE designed the study and was responsible for the collection of the Nottingham tissue micro-array data, HRA generated and scored the SEARCH tissue micro-array data, EP generated and scored the SEARCH tissue micro-array data, FB generated the SEARCH tissue micro-arrays, CC designed the study, and PDPP designed the study, was responsible for the collection of the SEARCH samples, carried out the statistical analysis and drafted the manuscript. All authors contributed to the editing of the draft manuscript and read and approved the final manuscript.

\section{Acknowledgements}

We thank all the patients who took part in the SEARCH study as well as all the clinicians who were part of the study team. SEARCH was funded through a programme grant from Cancer Research UK (C490/A10124) and this work is supported by the UK National Institute for Health Research Biomedical Research Centre at the University of Cambridge.

\section{Author details}

'Faculty of Health, Social Care \& Education, Anglia Ruskin University, Cambridge, UK. ${ }^{2}$ Division of Oncology, School of Medicine, University of Nottingham, Nottingham, UK. ${ }^{3}$ Department of Oncology, University of Cambridge, Strangeways Research Laboratory, Worts Causeway, Cambridge CB1 8RN, UK.

Received: 7 May 2014 Accepted: 20 November 2014

Published: 3 December 2014

\section{References}

1. Perou CM, Sorlie T, Eisen MB, van de Rijn M, Jeffrey SS, Rees CA, Pollack JR, Ross DT, Johnsen H, Akslen LA, Fluge O, Pergamenschikov A, Williams C, Zhu SX, Lonning PE, Borresen-Dale AL, Brown PO, Botstein D: Molecular portraits of human breast tumours. Nature 2000, 406(6797):747-752.

2. Sorlie T, Perou CM, Tibshirani R, Aas T, Geisler S, Johnsen H, Hastie T, Eisen MB, van de Rijn M, Jeffrey SS, Thorsen T, Quist H, Matese JC, Brown PO, Botstein D, Eystein Lonning P, Borresen-Dale AL: Gene expression patterns of breast carcinomas distinguish tumor subclasses with clinical implications. Proc Natl Acad SciUSA 2001, 98(19):10869-10874.

3. Curtis C, Shah SP, Chin SF, Turashvili G, Rueda OM, Dunning MJ, Speed D, Lynch AG, Samarajiwa S, Yuan Y, Graf S, Ha G, Haffari G, Bashashati A, Russell R, McKinney S, Langerod A, Green A, Provenzano E, Wishart G, Pinder S, Watson P, Markowetz F, Murphy L, Ellis I, Purushotham A, Borresen-Dale AL, Brenton JD, Tavare S, Caldas C, et al: The genomic and transcriptomic architecture of 2,000 breast tumours reveals novel subgroups. Nature 2012, 486(7403):346-352.

4. Carey LA, Perou CM, Livasy CA, Dressler LG, Cowan D, Conway K, Karaca G, Troester MA, Tse CK, Edmiston S, Deming SL, Geradts J, Cheang MC, Nielsen TO, Moorman PG, Earp HS, Millikan RC: Race, breast cancer subtypes, and survival in the Carolina Breast Cancer Study. JAMA 2006, 295(21):2492-2502.

5. Nielsen TO, Hsu FD, Jensen $K$, Cheang M, Karaca G, Hu Z, HernandezBoussard T, Livasy C, Cowan D, Dressler L, Akslen LA, Ragaz J, Gown AM, Gilks CB, van de Rijn M, Perou CM: Immunohistochemical and clinical characterization of the basal-like subtype of invasive breast carcinoma. Clin Cancer Res 2004, 10(16):5367-5374.

6. Ali HR, Dawson SJ, Blows FM, Provenzano E, Pharoah PD, Caldas C: Aurora kinase A outperforms Ki67 as a prognostic marker in ER-positive breast cancer. Br J Cancer 2012, 106(11):1798-1806.

7. Dowsett M, Nielsen TO, A'Hern R, Bartlett J, Coombes RC, Cuzick J, Ellis M, Henry NL, Hugh JC, Lively T, McShane L, Paik S, Penault-Llorca F, Prudkin L, Regan M, Salter J, Sotiriou C, Smith IE, Viale G, Zujewski JA, Hayes DF, International Ki-67 in Breast Cancer Working G: Assessment of Ki67 in Breast Cancer: recommendations from the International Ki67 in Breast Cancer Working Group. J Natl Cancer Inst 2011, 103(22):1656-1664.

8. Cheang MC, Chia SK, Voduc D, Gao D, Leung S, Snider J, Watson M, Davies S, Bernard PS, Parker JS, Perou CM, Ellis MJ, Nielsen TO: Ki67 index, HER2 status, and prognosis of patients with luminal B breast cancer. J Natl Cancer Inst 2009, 101(10):736-750.

9. Wishart GC, Azzato EM, Greenberg DC, Rashbass J, Kearins O, Lawrence G, Caldas C, Pharoah PD: PREDICT: a new UK prognostic model that predicts survival following surgery for invasive breast cancer. Breast Cancer Res 2010, 12(1):R1

10. Early Breast Cancer Trialists Collaborative Group: Effects of chemotherapy and hormonal therapy for early breast cancer on recurrence and 15-year survival: an overview of the randomised trials. Lancet 2005, 365(9472):1687-1717.

11. Wishart GC, Bajdik CD, Azzato EM, Dicks E, Greenberg DC, Rashbass J, Caldas C, Pharoah PD: A population-based validation of the prognostic model PREDICT for early breast cancer. Eur J Surg Oncol 2011, 37(5):411-417.

12. Wishart GC, Bajdik CD, Dicks E, Provenzano E, Schmidt MK, Sherman M, Greenberg DC, Green AR, Gelmon KA, Kosma VM, Olson JE, Beckmann MW, Winqvist R, Cross SS, Severi G, Huntsman D, Pylkas K, Ellis I, Nielsen TO, Giles G, Blomqvist C, Fasching PA, Couch FJ, Rakha E, Foulkes WD, Blows FM, Begin LR, Van't Veer LJ, Southey M, Nevanlinna $H$, et al: PREDICT Plus: development and validation of a prognostic model for early breast cancer that includes HER2. Br J Cancer 2012, 107(5):800-807.

13. Yerushalmi R, Woods R, Ravdin PM, Hayes MM, Gelmon KA: Ki67 in breast cancer: prognostic and predictive potential. Lancet Oncol 2010, 11(2):174-183.

14. Cuzick J, Dowsett M, Pineda S, Wale C, Salter J, Quinn E, Zabaglo L, Mallon E, Green AR, Ellis IO, Howell A, Buzdar AU, Forbes JF: Prognostic value of a combined estrogen receptor, progesterone receptor, Ki-67, and human epidermal growth factor receptor 2 immunohistochemical score and comparison with the Genomic Health recurrence score in early breast cancer. J Clin Oncol 2011, 29(32):4273-4278.

15. Aleskandarany MA, Rakha EA, Macmillan RD, Powe DG, Ellis IO, Green AR: MIB1/Ki-67 labelling index can classify grade 2 breast cancer into two clinically distinct subgroups. Breast Cancer Res Treat 2011, 127(3):591-599.

16. Pathmanathan N, Balleine RL: Ki67 and proliferation in breast cancer. J Clin Pathol 2013, 66(6):512-516.

17. van de Vijver MJ, He YD, van't Veer LJ, Dai H, Hart AA, Voskuil DW, Schreiber GJ, Peterse JL, Roberts C, Marton MJ, Parrish M, Atsma D, Witteveen A, Glas A, Delahaye L, van der Velde T, Bartelink H, Rodenhuis S, Rutgers ET, Friend 
$\mathrm{SH}$, Bernards R: A gene-expression signature as a predictor of survival in breast cancer. N Engl J Med 2002, 347(25):1999-2009.

18. Paik S, Shak S, Tang G, Kim C, Baker J, Cronin M, Baehner FL, Walker MG, Watson D, Park T, Hiller W, Fisher ER, Wickerham DL, Bryant J, Wolmark N: A multigene assay to predict recurrence of tamoxifen-treated, nodenegative breast cancer. N Engl J Med 2004, 351(27):2817-2826.

19. Parker JS, Mullins M, Cheang MC, Leung S, Voduc D, Vickery T, Davies S, Fauron C, He X, Hu Z, Quackenbush JF, Stijleman IJ, Palazzo J, Marron JS, Nobel AB, Mardis E, Nielsen TO, Ellis MJ, Perou CM, Bernard PS: Supervised risk predictor of breast cancer based on intrinsic subtypes. J Clin Oncol 2009, 27(8):1160-1167.

20. Dowsett M, Sestak I, Lopez-Knowles E, Sidhu K, Dunbier AK, Cowens JW, Ferree S, Storhoff J, Schaper C, Cuzick J: Comparison of PAM50 risk of recurrence score with oncotype DX and $\mathrm{IHC} 4$ for predicting risk of distant recurrence after endocrine therapy. J Clin Oncol 2013, 31(22):2783-2790.

21. Drukker CA, Nijenhuis MV, Bueno-de-Mesquita JM, Retel VP, van Tinteren H, Schmidt MK, van Harten WH, Sonke GS, Van't Veer LJ, Rutgers EJ, van de Vijver MJ, Linn SC: Optimized prediction of clinical outcome by the PREDICT plus tool and 70-gene signature in early stage node-negative breast cancer. In 36th Annual San Antonio Breast Cancer Symposium. San Antonio: American Association for Cancer Research; 2013.

22. Pathmanathan N, Balleine RL, Jayasinghe UW, Bilinski KL, Provan PJ, Byth K, Bilous AM, Salisbury EL, Boyages J: The prognostic value of Ki67 in systemically untreated patients with node-negative breast cancer. J Clin Pathol 2014, 67(3):222-228.

doi:10.1186/1471-2407-14-908

Cite this article as: Wishart et al:: Inclusion of KI67 significantly improves performance of the PREDICT prognostication and prediction model for early breast cancer. BMC Cancer 2014 14:908.

\section{Submit your next manuscript to BioMed Central and take full advantage of:}

- Convenient online submission

- Thorough peer review

- No space constraints or color figure charges

- Immediate publication on acceptance

- Inclusion in PubMed, CAS, Scopus and Google Scholar

- Research which is freely available for redistribution 